ORIGINAL ARTICLE

\title{
Is readmission to hospital an indicator of poor process of care for patients with heart failure?
}

\author{
J C Luthi, B Burnand, W M McClellan, S R Pitts, W D Flanders
}

See editorial commentary, p 10

Qual Saf Health Care 2004;13:46-51. doi: 10.1136/qshc.2003.006999

See end of article for authors' affiliations ......................

Correspondence to: Dr J C Luthi, Health Care Evaluation Unit, Institute of Social and Preventive Medicine, University of Lausanne, Bugnon 17, $\mathrm{CH}-1005$ Lausanne, Switzerland;

Jean-Christophe.Luthi @inst.hospvd.ch

Received 1 May 2003 Accepted

28 November 2003
Background: Controversy exists about the appropriateness of using readmission as an indicator of the quality of care. A study was undertaken to measure the validity and predictive ability of readmission in this context.

Methods: An evaluation study was performed in patients discharged alive with heart failure from three Swiss academic medical centres. Process quality indicators were derived from evidence based guidelines for the management and treatment of heart failure. Readmissions were calculated from hospital administrative data. The predictive ability of readmissions was evaluated using bivariate and multivariate analyses, and validity by calculating sensitivity, specificity, positive and negative predictive value, using process indicators as the "gold standard".

Results: Of 1055 eligible patients discharged alive, 139 (13.2\%) were readmitted within 30 days. The adjusted odds ratio (OR) for absence of measurement of left ventricular function was $0.70195 \% \mathrm{Cl} 0.45$ to 1.08) for readmissions. In patients with left ventricular systolic dysfunction, three dose categories of angiotensin converting enzyme inhibitor were examined using ordinal logistic regression. The adjusted OR for these categories was 1.07 (95\% $\mathrm{Cl} 0.56$ to 2.06$)$ for readmissions. When using process indicators as the gold standard to assess the validity of readmissions, sensitivity ranged from 0.08 to 0.17 and specificity from 0.86 to 0.93 .

Conclusions: Readmission did not predict and was not a valid indicator of the quality of care for patients with heart failure admitted to three Swiss university hospitals. l is uncertain whether routinely collected data can be used for a valid evaluation of quality of care. The nature and quality of these variables are also dependent on the type of data recorded and the collection system in place. Outcome measures such as readmissions have often been proposed as indicators of the quality of care. ${ }^{1-4}$ Early readmission has several features that make it very appealing as a quality indicator. It is a costly pattern of hospital use with a common occurrence. Depending on the diagnosis, $5-29 \%$ of adults are readmitted to the same hospital within 1 month, ${ }^{5}$ and readmission rates have been shown to approach $50 \%$ within 6 months for patients discharged with heart failure (HF). ${ }^{67}$ Readmission is also attractive as a sentinel quality indicator because it is easily computed and can be identified from administrative data. ${ }^{8}$

However, the link between early readmission and quality of care is still uncertain. Some studies have found a relationship between substandard patient care and early readmission, ${ }^{19}$ and a systematic review indicated that, on average, substandard care increases the risk of early readmission by $24 \%{ }^{9}$ Other studies have shown that demographic characteristics, medical history, and comorbidity are correlated with early readmission, specifically in patients with HF. ${ }^{6}{ }^{10}{ }^{11}$ These doubts about the use of readmission to measure the quality of care for patients with HF has led the American Heart Association/American College of Cardiology (AHA/ACC) Scientific Forum on Quality of Care and Outcomes Research in Cardiovascular Disease and Stroke to publish recommendations about the evaluation of the quality of care in patients with HF. Given the current limitations of available outcome measures, particularly the lack of appropriate risk adjustment methods, the group does not recommend the use of readmission for comparing healthcare providers for patients with HF. ${ }^{12}$ The aim of our study was to assess the validity and predictive ability of routinely collected readmission data as a quality of care indicator.

\section{METHODS}

\section{Study design}

An evaluation study was conducted in three Swiss academic medical centres. A retrospective cohort study was performed to assess whether chart based process indicators were risk factors for administrative outcome indicators (readmission) for patients admitted to hospital with HF. We found that, in patients with $\mathrm{HF}$, the determination of ventricular function was associated with hospital mortality but process indicators derived from evidence based guidelines were not related to early readmission. These results have been published elsewhere. ${ }^{13}$ We then examined the reverse association-that is, whether readmission could be used as a measure to predict quality of care. The rationale for the direction of this analysis follows the logic of using readmission as a quality of care indicator that should predict change in the quality of process. This logic does not, however, follow a time sequence and might appear counterintuitive, but this should not be a problem because the nature of the relation examined is not time related and the measure of the dependent variable (readmission) does not influence the measure of the independent variable (guideline derived process indicators). We also assessed the validity of readmission as a quality indicator using process indicators as the gold standard.

\section{Setting and patients}

The three hospitals which participated in the study are urban public university hospitals and are the major primary care hospitals for their respective areas. All the study patients were discharged between 1 January and 31 December 1999 with a principal or secondary diagnosis of HF using the International Classification of Disease 10th revision (ICD-10) 
codes I50.0, I50.1, I50.9, I1 1.0, I13.0 and I13.2. In two of the hospitals 976 and 774 eligible patients were found, 700 of which were randomly selected in each centre based on our power calculation. In the third hospital the quality of the administrative data was not so good and we were able to select only 234 eligible patients. Patients were excluded from the study if they had died during the hospital stay or if they had left the hospital against medical advice, were transferred to another acute care facility, were discharged in 1998, or had secondary heart failure due to valvular heart disease, acute myocardial infarction, cor pulmonale, chronic renal failure, hyperthyroidosis, thiamine deficiency, amyloidosis, or chronic obstructive lung disease treated with oxygen.

\section{Data collection}

Data abstraction was conducted by trained doctors or medical record specialists. In two hospitals the entire medical charts were available for data abstraction while, in the third, only the electronic medical records which included the discharge letter, laboratory results, and all cardiological procedures were available. Demographic characteristics, risk factors, symptoms and findings at admission, and discharge details were taken from the medical records. Thirty day readmissions were calculated using administrative data. All cause readmissions were assessed and only patients from the index hospital were included but, because these hospitals are university referral centres, each for a different catchment area, we assumed that only a few patients could have been readmitted to a different hospital. Furthermore, for one provider we could establish that no patients were readmitted to another Swiss hospital using a unique identifier from the Swiss Federal Statistical Office. While we would have liked to include only unplanned readmissions in the definition, this was impossible with the database available. We were also not able to exclude from the readmission denominator patients who died outside hospital within 30 days of discharge.

\section{Process quality indicators}

Process quality indicators have been developed from evidence based guidelines ${ }^{14-18}$ and used in previous studies. ${ }^{19-21}$ They were adapted to the Swiss setting in collaboration with key clinicians. Table 1 summarises these quality indicators with their respective level of evidence.

The first quality indicator was the proportion of patients with HF who had a measurement of left ventricular function (LVF). LVF was identified in the chart by the presence of a previously measured ejection fraction by echocardiography, cardiac catheterisation, radionuclide ventriculography, or by a narrative statement in the chart. Left ventricular systolic dysfunction (LVSD) was defined as any measured value of the ejection fraction equal to or less than $40 \%$ documented in the chart from a previous or current hospital admission or by a narrative statement.

For the second quality indicator (angiotensin converting enzyme inhibitor (ACEI) by dose level) we included only patients with LVSD and recorded all ACEI and angiotensin receptor blockers (ARB) prescribed at discharge. We further measured the proportion of patients discharged on ACEI who received the target dose. The target dose was defined as that found to increase survival in patients with LVSD in controlled clinical trials. Target doses were defined as: captopril $50 \mathrm{mg}$ three times daily, enalapril $10 \mathrm{mg}$ twice daily, lisinopril $20 \mathrm{mg}$ once daily, and ramipril $5 \mathrm{mg}$ twice daily. ${ }^{22}$ If evidence from clinical trials was not available, target dose levels were based on the manufacturers' stated average doses which were as follows: benazapril $20 \mathrm{mg}$ once daily, fosinopril $20 \mathrm{mg}$ once daily, quinapril $10 \mathrm{mg}$ twice daily, perindopril $4 \mathrm{mg}$ once daily, and cilazapril $1 \mathrm{mg}$ once daily. ${ }^{23}$ Finally, we defined three treatment groups: (1) no ACEI at discharge, (2) suboptimal dose of ACEI, and (3) target dose of ACEI or ARB (any dose). Patients with any known contraindications to ACEI were excluded from the analysis.

The third quality indicator was the prescription at discharge of all $\beta$ blockers for systolic dysfunction. All $\beta$ blockers prescribed at discharge were recorded, and only patients with LVSD and no contraindication to $\beta$ blockers were included.

The fourth quality indicator was the prescription of anticoagulants at discharge in patients with atrial fibrillation. Only patients with atrial fibrillation and no contraindication

Table 1 Guidelines for the diagnosis and management of heart failure with level of evidence

\begin{tabular}{|c|c|c|c|}
\hline & Quality indicator & Guideline & $\begin{array}{l}\text { Level of evidence } \\
\text { (ACC) }{ }^{*}\end{array}$ \\
\hline 1 & $\begin{array}{l}\text { Determination of left } \\
\text { ventricular function }\end{array}$ & $\begin{array}{l}\text { Patients with suspected HF should undergo } \\
\text { echocardiography or radionuclide ventriculography to } \\
\text { measure the ejection fraction (if information about } \\
\text { ventricular function is not available from previous tests). }\end{array}$ & Class I, level C \\
\hline 2 & $\begin{array}{l}\text { Use and dosing of ACEI } \\
\text { in patients with LVSD }\end{array}$ & $\begin{array}{l}\text { Patients with LVSD should be given trial of ACEls unless } \\
\text { contraindicated. Doses of ACEls should be titrated } \\
\text { upwards to the doses shown to decrease mortality in } \\
\text { large randomised controlled trials. }\end{array}$ & Class I, level A \\
\hline 3 & $\begin{array}{l}\text { Use of } \beta \text { blocker in } \\
\text { patients with LVSD* }\end{array}$ & $\begin{array}{l}\text { Patients with stable NYHA class II and III HF due to } \\
\text { LVSD should receive a } \beta \text { blocker unless contraindicated. }\end{array}$ & Class I, level A \\
\hline 4 & $\begin{array}{l}\text { Use of warfarin in } \\
\text { patients with } \mathrm{HF} \text { and } \\
\mathrm{AF}^{* \star}\end{array}$ & $\begin{array}{l}\text { HF patients with a history of systemic or pulmonary } \\
\text { embolism, recent } A F \text {, or mobile left ventricular thrombi } \\
\text { should be anticoagulated to a prothrombin time ratio of } \\
1.2-1.8 \text { times each individual laboratory control time } \\
\text { (INR 2.0-3.0). }\end{array}$ & Class I, level A \\
\hline
\end{tabular}

$\mathrm{ACEI}=$ angiotensin converting enzyme inhibitor; $\mathrm{LVSD}=$ left ventricular systolic dysfunction; $\mathrm{HF}=$ heart failure; $\mathrm{AF}=$ atrial fibrillation; $\mathrm{INR}=$ international normalisation ratio. ${ }^{*} \mathrm{ACC}=$ American College of Cardiology rating system; class I: conditions for which there is evidence and/or general agreement that a given procedure/therapy is useful and effective; class II: conditions for which there is conflicting evidence and/or a divergence of opinion about the usefulness/efficacy of performing the procedure/ therapy; class III: conditions for which there is evidence and/or general agreement that a procedure/therapy is not useful/effective and in some cases may be harmful; level A: data derived from multiple randomised clinical trials; level B: data derived from a single randomised trial or non-randomised studies; level C: when consensus opinion of experts was the primary source of recommendation. ${ }^{14}$

**Anticoagulation for atrial fibrillation not discussed in ACC heart failure guidelines but in ACC guidelines for the management and treatment of patients with atrial fibrillation. ${ }^{34}$ 


\begin{tabular}{|c|c|c|c|}
\hline \multirow[b]{2}{*}{ Patient characteristics } & \multicolumn{3}{|c|}{30 day readmission } \\
\hline & $\mathrm{N}$ & $\begin{array}{l}\text { No }(\%) \text { readmitted } \\
(\mathrm{N}=139)\end{array}$ & p value \\
\hline Age (years)* & 75.0 (12.8) & $73.1(13.0)$ & 0.056 \\
\hline $\operatorname{Sex}(n=1054)$ & & & 0.404 \\
\hline Male & 572 & $80(14.0)$ & \\
\hline Female & 482 & 59 (12.2) & \\
\hline Previous history of HF ( $n=973$ ) & 550 & $62(11.3)$ & 0.094 \\
\hline Prior Ml $(n=1034)$ & 340 & 40 (11.8) & 0.423 \\
\hline COPD, bronchitis, emphysema ( $n=1032)$ & 202 & 38 (18.8) & 0.005 \\
\hline Hypertension $(n=1038)$ & 634 & $83(13.1)$ & 0.918 \\
\hline Diabetes $(n=1041)$ & 244 & 41 (16.8) & 0.048 \\
\hline Current smoker $(n=1015)$ & 156 & 30 (19.2) & 0.010 \\
\hline \multicolumn{4}{|l|}{ Symptoms and findings } \\
\hline PND $(n=729)$ & 177 & $30(17.0)$ & 0.087 \\
\hline $\mathrm{DOE}(\mathrm{n}=958)$ & 735 & $95(12.9)$ & 0.706 \\
\hline Orthopnoea $(n=774)$ & 353 & $52(14.7)$ & 0.386 \\
\hline Leg oedema $(n=900)$ & 475 & 64 (13.5) & 0.814 \\
\hline Pulmonary rales $(n=928)$ & 542 & $61(11.3)$ & 0.113 \\
\hline S3 gallop $(n=874)$ & 37 & $3(8.1)$ & 0.613 \\
\hline$J V D(n=809)$ & 258 & 38 (14.7) & 0.276 \\
\hline Atrial fibrillation $(n=888)$ & 249 & $29(11.7)$ & 0.338 \\
\hline
\end{tabular}

to anticoagulants were included. Atrial fibrillation was recorded on the ECG report during hospitalisation.

Interrater reliability was assessed in one hospital by a random replicate sample of 100 charts which were reabstracted. ${ }^{24}$ The kappa values for quality of care measures were 0.91 for the determination of LVF, 1.00 for target dose ACEI versus less than target dose, 0.50 for $\beta$ blockers in patients with LVSD, and 1.00 for anticoagulants for atrial fibrillation.

\section{Statistical analysis}

Bivariate analyses were performed using $\chi^{2}$ tests, Fisher's exact tests, or $t$ tests as appropriate, followed by multivariate analyses. A logistic regression for dichotomous outcomes and an ordinal logistic regression when the dependent variable had three categories (ACEI by dose level) were performed. Selection of the variables included in the model was based on a priori consulting of bivariate results. The fit of all models was good and no collinearity problems were found.$^{25-27}$ It was not possible to implement a correlated data analysis taking into account hierarchical structure of the data because there were only three hospitals in the study and this type of analysis requires a minimum of four. To test the validity of readmission we assumed that chart based process indicators represent care actually received and can be used as a gold standard. Sensitivity, specificity, positive predictive value and negative predictive value were measured. Positive and negative likelihood ratios were also computed. ${ }^{28-30}$ We tested the validity of readmission by using process quality indicators as gold standard. All analyses were done with SAS software (SAS Institute Inc, Cary, NC, USA).

\section{RESULTS}

Of 1634 eligible patients discharged from three Swiss academic medical centres between l January and 31 December 1999, we excluded 134 patients who transferred to another acute care facility, six patients who left the hospital against medical advice, and four patients with an uncertain date of discharge. We also excluded 306 patients for one or more of the following conditions: aortic stenosis $(n=111)$, acute myocardial infarction $(n=107)$, chronic renal failure on dialysis $(n=31)$, heart failure attributed to thyrotoxicosis $(\mathrm{n}=30)$, cor pulmonale or chronic obstructive pulmonary disease $(\mathrm{COPD})$ requiring home oxygen $(\mathrm{n}=30)$,

Table 3 Association between characteristics of patients with heart failure during hospital stay and readmissions $(\mathrm{N}=1055)$

\begin{tabular}{llcl}
\hline & \multicolumn{3}{l}{30 day readmission } \\
\cline { 2 - 4 } Patient characteristics & N or mean (SD) & $\begin{array}{l}\text { No (\%) readmitted or } \\
\text { mean (SD) (N=139) }\end{array}$ & p valuet \\
\hline HF confirmed by chest radiography $(\mathrm{n}=695)$ & 399 & $56(14.0)$ & 0.322 \\
Potassium (mmol/l, $\mathrm{n}=1006)^{*}$ & $4.1(0.6)$ & $4.1(0.5)$ & 0.982 \\
Creatinine $(\mathrm{mmol} / \mathrm{I}, \mathrm{n}=1007)^{*}$ & $109.8(44.6)$ & $109.8(39.7)$ & 0.999 \\
Minimum ejection fraction $(\%, \mathrm{n}=506)^{*}$ & $36.5(15.6)$ & $39.1(14.7)$ & 0.112 \\
Charlson comorbidity index $(\mathrm{n}=1055)^{*}$ & $1.91(1.42)$ & $2.10(1.60)$ & 0.131 \\
Consultation with cardiologist $(\mathrm{n}=1038)$ & 571 & $80(14.0)$ & 0.287 \\
ACEl on admission $(\mathrm{n}=982)$ & 410 & $47(11.5)$ & 0.353 \\
Length of stay (days, $\mathrm{n}=1055)^{*}$ & $14.0(15.0)$ & $15.2(13.7)$ & 0.314 \\
\hline
\end{tabular}

$\mathrm{HF}=$ heart failure; $\mathrm{ACEl}=$ angiotensin converting enzyme inhibitor .

*Values are mean (SD).

†Readmitted versus not readmitted. 


\begin{tabular}{|c|c|c|c|}
\hline \multirow[b]{2}{*}{ Patient characteristics } & \multicolumn{3}{|c|}{30 day readmission } \\
\hline & $\mathbf{N}$ & $\begin{array}{l}\text { No }(\%) \text { readmitted } \\
(\mathrm{N}=139)\end{array}$ & p value* \\
\hline \multicolumn{4}{|l|}{ Discharge counselling } \\
\hline Low sodium diet $(n=1022)$ & 33 & $6(18.2)$ & 0.427 \\
\hline Daily weight $(n=1024)$ & 43 & $9(20.9)$ & 0.159 \\
\hline Smoking cessation $(n=143)$ & 11 & $4(36.4)$ & 0.220 \\
\hline \multicolumn{4}{|l|}{ Discharge medications $(n=1015)$} \\
\hline Anticoagulants & 309 & $39(12.6)$ & 0.900 \\
\hline$\beta$ blocker & 147 & $19(12.9)$ & 0.967 \\
\hline Calcium blocker & 145 & 23 (15.9) & 0.235 \\
\hline Digoxin & 334 & 37 (11.1) & 0.221 \\
\hline Diuretics & 642 & 77 (12.0) & 0.309 \\
\hline Nitrates & 311 & 41 (13.2) & 0.818 \\
\hline Angiotensin receptor blockers & 88 & $12(13.6)$ & 0.741 \\
\hline Spironolactone & 122 & $17(13.4)$ & 0.666 \\
\hline
\end{tabular}

mitral stenosis $(n=9)$, amyloidosis $(n=5)$, and thiamine deficiency $(\mathrm{n}=1)$. We further excluded 98 who died during their hospital stay.

A total of 1055 patients discharged alive with HF were therefore included in the analysis. The mean (SD) age was 75.0 ( 12.8 ) years and $45.7 \%$ were women. The distribution of risk factors among these patients was as follows: $56.5 \%$ had a previous history of HF, $32.9 \%$ prior myocardial infarction, $19.6 \%$ COPD, bronchitis or emphysema, $61.1 \%$ hypertension, $23.4 \%$ diabetes, and $15.4 \%$ were current smokers. The mean (SD) minimum ejection fraction was 36.5 (15.6)\%, mean (SD) Charlson comorbidity index was 1.91 (1.42), and mean (SD) length of stay was 14.0 (15.0) days.

\section{Predictive ability of outcome indicators Bivariate analysis}

Associations between demographic characteristics, characteristics of patients at admission and when in hospital, and readmissions are shown in tables 2 and 3. Of the 1055 patients, $139(13.2 \%)$ were readmitted within 30 days. Patients with COPD, bronchitis, or emphysema were more likely to be readmitted $(18.8 \%, p=0.005)$, as were patients with diabetes mellitus $(16.8 \%, \mathrm{p}=0.048)$ and current smokers $(19.2 \%, \mathrm{p}=0.010)$. Patients readmitted had a mean (SD) length of stay of 15.2 (13.7) days which was only slightly longer than the length of stay of patients not readmitted (table 3). Associations between readmissions and discharge characteristics are shown in table 4 .

\section{Multivariate analysis}

The results of the multivariate analysis are presented in table 5. As covariate we included only variables available in the hospital discharge data. After controlling for hospitals, the risk of LVF not being determined was 0.70 times higher in patients who were readmitted than in patients not readmitted. This relationship was not statistically significant $(\mathrm{p}=0.103)$. Readmissions were also not associated with the three treatment categories of ACEI in patients with LVSD. The adjusted OR (95\% CI) from the ordinal logistic regression for the effect of the three categories (no ACEI, less than target ACEI dose, and target dose of ACEI or ARB) was 1.07 (0.56-2.06), $\mathrm{p}=0.840$. Readmissions were also not associated with the prescription of $\beta$ blockers in patients with LVSD or of anticoagulants in patients with atrial fibrillation.

\section{Validity and discriminating power of readmissions}

The validity and discriminating power of readmissions as predictors of process of care quality indicators are presented in table 6 . We tested the validity of readmissions by using process quality indicators as the gold standard. For all the potential associations examined the sensitivity was $0.08-$ 0.17 , specificity $0.86-0.88$, positive predictive value $0.16-0.43$, negative predictive value $0.61-0.80$, positive likelihood ratio 0.58-1.24, and negative likelihood ratio 0.96-1.06.

\section{DISCUSSION}

In this analysis we found that readmission to hospital was not associated with the quality of care for patients with HF and that it has low specificity and sensitivity. These findings provide new evidence that the use of this outcome as a quality of care indicator is limited, at least when it is measured from routinely collected data-that is, independent of clinical or other events that may indicate that the readmission occurred probably not because of a quality of

Table 5 Association between readmissions and process indicators $(\mathrm{N}=1055)$

\begin{tabular}{|c|c|c|c|c|c|c|}
\hline \multirow[b]{2}{*}{ Process indicator } & \multicolumn{3}{|c|}{ Crude analysis } & \multicolumn{3}{|c|}{ Adjusted analysis } \\
\hline & OR & $95 \% \mathrm{Cl}$ & $\mathrm{p}$ value & OR & $95 \% \mathrm{Cl}$ & $\mathrm{p}$ value \\
\hline $\begin{array}{l}\text { LVF not determined } \\
\text { Level of ACEI dose if LVSD }(n=370)\end{array}$ & 0.68 & 0.44 to 1.04 & 0.063 & $0.70^{*}$ & 0.45 to 1.08 & 0.103 \\
\hline $\begin{array}{l}\text { No ACEI } \\
\text { Less than target dose ACEI } \\
\text { Target dose ACEI or ARB }\end{array}$ & $\begin{array}{l}0.68 \\
1.29 \\
1.00\end{array}$ & $\begin{array}{l}0.19 \text { to } 1.92 \\
0.65 \text { to } 2.52\end{array}$ & $\begin{array}{l}0.447 \\
0.431\end{array}$ & $1.07^{* *}$ & 0.56 to 2.06 & 0.840 \\
\hline No $\beta$ blockers if LVSD $(n=297)$ & 1.14 & 0.47 to 2.85 & 0.757 & $1.21^{*}$ & 0.52 to 2.84 & 0.647 \\
\hline No anticoagulants if $A F(n=211)$ & 0.54 & 0.17 to 1.53 & 0.260 & $0.62^{*}$ & 0.23 to 1.69 & 0.354 \\
\hline
\end{tabular}

$\mathrm{LVF}=$ left ventricular function; $\mathrm{ACEI}=$ angiotensin converting enzyme inhibitor; $\mathrm{LVSD}=$ left ventricular systolic dysfunction; $\mathrm{ARB}=$ angiotensin receptor blockers; $\mathrm{AF}=$ atrial fibrillation.

${ }^{*}$ Controlling for hospitals.

**Results from the ordinal logistic regression summarising the effect of the three categories and controlling for hospitals. 
Table 6 Validity of readmissions using process indicators as the gold standard for patients with heart failure $(N=1055)$

\begin{tabular}{|c|c|c|c|c|c|c|}
\hline Indicators & $\begin{array}{l}\text { Sensitivity } \\
(95 \% \mathrm{Cl})\end{array}$ & $\begin{array}{l}\text { Specificity } \\
\text { (95\% CI) }\end{array}$ & $\begin{array}{l}\text { Positive } \\
\text { predictive value } \\
(95 \% \mathrm{CI})\end{array}$ & $\begin{array}{l}\text { Negative } \\
\text { predictive value } \\
(95 \% \mathrm{Cl})\end{array}$ & $\begin{array}{l}\text { Positive } \\
\text { likelihood ratio }\end{array}$ & $\begin{array}{l}\text { Negative } \\
\text { likelihood ratio }\end{array}$ \\
\hline $\begin{array}{l}\text { Readmissions/determination } \\
\text { of LVF }(n=1055) \\
\text { Readmissions/level of ACEI } \\
\text { dose if LVSD }(n=370)\end{array}$ & $0.10(0.08$ to 0.12$)$ & 0.86 (0.83 to 0.88$)$ & $0.24(0.21$ to 0.26$)$ & $0.68(0.66$ to 0.71$)$ & 0.71 & 1.05 \\
\hline No ACEI & $0.10(0.06$ to 0.13$)$ & $0.86(0.82$ to 0.91$)$ & $0.16(0.11$ to 0.20$)$ & $0.79(0.73$ to 0.84$)$ & 0.71 & 1.05 \\
\hline Less than target dose ACEI & $0.17(0.13$ to 0.21$)$ & $0.86(0.83$ to 0.90$)$ & $0.43(0.37$ to 0.48$)$ & $0.63(0.58$ to 0.69$)$ & 1.24 & 0.96 \\
\hline Target dose ACEI or ARB & Reference & Reference & Reference & Reference & Reference & Reference \\
\hline $\begin{array}{l}\text { Readmission/ } \beta \text {-blockers if LVSD } \\
(\mathrm{n}=297)\end{array}$ & $0.14(0.10$ to 0.18$)$ & $0.88(0.84$ to 0.91$)$ & 0.22 (0.17 to 0.27$)$ & 0.80 (0.77 to 0.85$)$ & 1.12 & 0.98 \\
\hline $\begin{array}{l}\text { Readmission/anticoagulants if } A F \\
(\mathrm{~N}=211)\end{array}$ & $0.08(0.04$ to 0.11$)$ & 0.87 (0.82 to 0.92$)$ & 0.26 (0.20 to 0.32$)$ & 0.61 (0.54 to 0.67$)$ & 0.58 & 1.06 \\
\hline
\end{tabular}

$\mathrm{LVF}=$ left ventricular function; $\mathrm{ACE}=$ angiotensin converting enzyme inhibitor; $\mathrm{LVSD}=$ left ventricular systolic dysfunction; $\mathrm{ARB}=$ angiotensin receptor blockers; $\mathrm{AF}=$ atrial fibrillation.

care problem. One possible explanation for our negative results is that we were not able to measure the intervening variables between process of care and outcome such as changes in disease status and consequent clinical course or other events that may account for the readmission.

Several studies have shown similar patterns. ${ }^{5132}$ In a recent study performed in a Swiss university hospital, early readmission by patients with HF was not associated with the quality of care while in hospital, particularly admission work up, evaluation and treatment during the patient's stay. However, the authors did show that readmission was strongly related to patient characteristics including age, previous diagnosis of HF, and prior myocardial revascularisation. ${ }^{11}$ Other studies have shown similar relationships between patient characteristics and readmissions. ${ }^{6710}$

Despite these results, conflict about the validity of readmission as a quality indicator still remains. Early readmission is sometimes interpreted as a problem following discharge due to inadequate care during the hospital stay, but other factors occurring after discharge may contribute to readmission. Several studies, including a meta-analysis, have shown that readmissions are associated with the quality of care. ${ }^{1933}$

Given these conflicting results, the current limitations of routinely available outcome measures such as readmissions and the lack of valid risk adjustment methods, the AHA/ACC Scientific Forum on Quality of Care and Outcome Research in Cardiovascular Disease and Stroke does not recommend the use of readmission for comparing hospitals for patients with HF. However, this outcome measure might be documented and recorded over time and included as part of quality improvement projects within institutions. ${ }^{12}$ It is particularly important to understand the limitations of outcome measurements. Despite major advances in the last decade, our ability to adjust outcomes for severity of illness, comorbidity, and other patient related risk factors is still crude and limited.

One limitation of this study is that the available data did not allow us to differentiate between planned and unplanned readmissions, which might have resulted in misclassification bias. Another limitation is the use of process measures as a gold standard to assess the validity of outcome indicators. We know that perfect quality of care is an abstract concept that cannot be exactly measured. The process indicators used were the best available and were therefore designated as "the gold standard". But these indicators are far from perfect. A further limitation of the study was that the quality of the administrative data was heterogeneous between providers. Specifically, we were able to select only 234 patients with ICD-10 HF codes from one university hospital compared with 976 and 774 patients from the others, creating a potential selection bias.

\section{Key messages}

- Uncertainty exists as to whether routinely collected data can be used to assess quality of care in hospitals.

- Controversy exists about the appropriateness of using hospital readmission as an indicator of quality of care.

- In a multivariate logistic analysis no significant associations were found between readmissions and process quality indicators in patients with heart failure.

- Routinely determined readmission did not predict and was not a valid indicator of the quality of care for patients with heart failure.

In conclusion, we found further evidence that early readmission, measured using routinely collected data, is a poor predictor of quality of care indicators for patients with HF. Our findings are consistent with recommendations from the AHA/ACC Scientific Forum on Quality of Care and Outcome Research in Cardiovascular Disease and Stroke to be cautious in using readmissions as quality indicators to compare healthcare providers until the definition and measurement of this variable is improved and new appropriate risk adjustment methods are available.

\section{Authors' affiliations}

J C Luthi, B Burnand, Institute of Social and Preventive Medicine, University of Lausanne, Switzerland

J C Luthi, Health Observatory, Canton of Valais, Switzerland J C Luthi, W M McClellan, S R Pitts, W D Flanders, Epidemiology Department, Rollins School of Public Health, Emory University, Atlanta, Georgia, USA

W M McClellan, Georgia Medical Care Foundation, Atlanta, Georgia, USA

\section{REFERENCES}

1 Ashton CM, Kuykendall DH, Johnson NL, et al. The association between the quality of inpatient care and early readmission. Ann Intern Med 1995; 122:415-21.

2 Milne R, Clarke A. Can readmission rates be used as outcome indicator? BMJ 1990;301:1139-40.

3 Frankl SE, Breeling JL, Goldman L. Preventability of emergent hospital readmissions. Am J Med 1991;90:667-74.

4 Rich NW, Beckham V, Wittenberg C, et al. A multidisciplinary intervention to prevent the readmission of elderly patients with congestive heart failure. N Engl J Med 1995;333:1190-5.

5 Thomas JW, Holloway JJ. Investigating early readmission as an indicator for the quality of care studies. Med Care 1991;29:377-94.

6 Krumholz HM, Parent EM, Tu N, et al. Readmission of the hospitalization for congestive heart failure among Medicare beneficiaries. Arch Intern Med 1997; 157:99-104. 
7 Krumholz HM, Chen YT, Wang Y, et al. Predictors of readmission among elderly survivors of admission with heart failure. Am Heart J 2000;139:72-7.

8 Anderson GF, Steinberg EP. Hospital readmissions in the Medicare population. N Engl J Med 1984;311:1349-53.

9 Ashton CM, del Junco DJ, Mansyur C, et al. The association between the quality of inpatient care and early readmission: a meta-analysis of the evidence. Med Care 1997;35:1044-59.

10 Chin MH, Goldman L. Correlates of early hospital readmissions or death in patients with congestive heart failure. Am J Cardiol 1997;79:1640-4.

11 Kossovsky NP, Sarasin FP, Perneger TV, et al. Unplanned readmissions of patients with congestive heart failure: do they reflect in-hospital quality of care or patients characteristics? Am J Med 2000;109:386-90.

12 Krumholz HM, Baker DW, Ashton CM, et al. Evaluating quality of care for patient with heart failure. American Heart Association/American College of Cardiology Conference proceedings. Circulation 2000;101:e122-40.

13 Luthi JC, Flanders WD, Pitts SR, et al. Outcomes and the quality of care for patients hospitalized with heart failure. Int J Qual Health Care 2004 (in press)

14 Williams JF, Bristow MR, Fowler MB, et al. Guidelines for the evaluation and management of heart failure: report of the American College of Cardiology/ American Heart Association Task Force on Practice Guidelines (Committee on Evaluation and Management of Heart Failure). J Am Coll Cardiol 1995;26:1376-98.

15 Konstam MA, Dracup K, Baker DW, et al. Heart failure: evaluation and care of patients with left-ventricular systolic dysfunction. Clinical practice guideline no 11. Publication No AHCPR 94-0612). Rockville, MD: Agency for Health Care Policy and Research, Public Health Service, US Department of Health and Human Services, 1994.

16 Hunt SA, et al. Evaluation and management of chronic heart failure in the adult: ACC/AHA practice guidelines. J Am Coll Cardiol 2001;38:2101-13.

17 European Society of Cardiology. Guidelines for the diagnosis of heart failure. Eur Heart J 1999; 16:741-5.

18 Kiowski W, Dubach $\mathrm{P}$, Mohacsi $\mathrm{P}$, et al. Arbeitsgruppe für Herzinsuffizienz der schweizerischen Gesellschaft für Kardiologie. Empfehlungen zur Diagnose und Behandlung der chronischen Herzinsuffizienz. Bull Médecins Suisses 2002;83:1233-42.
19 Jencks SF, Cuerdon T, Buwend R, et al. Quality of medical care delivered to medical benefiaciaries, a profile of state and national levels. JAMA 2000;284: 1670-6.

20 Luthi JC, McClellan WM et al. Variations among hospitals in the quality of care for heart failure. Eff Clin Pract 2000;3:69-77.

21 Krumholz HM, Wang Y, Parent EM, et al. Quality of care for elderly patients hospitalized with heart failure. Arch Intern Med 1997;157:2242-7.

22 Cleland JGF, Hubbard WN, Pittard J, et al. ACE inhibitors in heart failure: what dose? BMJ 1995;71:65-6.

23 Compendium Suisse des Medicaments. Basle, Switzerland: Documend SA, 2000.

24 Guggenmoos-Holtzmann I. The meaning of kappa: probalistic concepts of reliability and validity revisited. J Clin Epidemiol 1996;49:775-82.

25 Kleinbaum DG. Logistic regression. A self learning text. New York: SpringerVerlag, 1994.

26 Kleinbaum DG, Kupper LL, Morgenstern H. Applied regression analysis and other multivariate methods. Belmont: Duxbury Press, 1988.

27 Hosmer DW, Lemeshow S. Applied logistic regression. New York: WileyInterscience, 1989.

28 Diamond GA. The wizard of odds: Bayes'theorem and diagnostic testing. Mayo Clin Proc 1999;74:1179-82.

29 Weissler AM. A perspective on standardizing the predictive power of noninvasive cardiovascular tests by likelihood ratio computation: 1 . Mathematical principles. Mayo Clin Proc 1999;74:1061-71.

30 Weissler AM. A perspective on standardizing the predictive power of noninvasive cardiovascular tests by likelihood ratio computation: 2 . Clinical applications. Mayo Clin Proc 1999;74:1072-87.

31 Hofer TP, Hayward RA. Can early readmission rates accurately detect poor quality hospitals? Med Care 1995;33:234-45.

32 Thomas JW. Does risk-adjusted readmission rate provide valid information on hospital quality? Inquiry 1996;28:258-70.

33 Ludke RL, Booth DM, Lewis-Beck JA. Relationship between early readmission and hospital quality of care indicators. Inquiry 1993;30:95-103.

34 Fuster V, Ryden LE, et al. ACC/AHA/ESC guidelines for the management and treatment of patients with atrial fibrillation. J Am Coll Cardiol 2001;38:1266i-1xx. 